Original Research Article

\title{
Knowledge, attitude and practices towards pharmacovigilance among health care professionals in a teaching and general hospital of South India
}

\author{
Zainab Ghazala*, Prakash Kalshetty, Shrenik Vardhamane
}

Department of Pharmacology, Khaja Bandanawaz Institute of Medical Sciences, Kalaburagi, Karnataka, India

Received: 12 January 2019 Accepted: 18 January 2019

\section{*Correspondence to: \\ Dr. Zainab Ghazala, \\ Email: zainab.ghazala@ gmail.com}

Copyright: (C) the author(s), publisher and licensee Medip Academy. This is an openaccess article distributed under the terms of the Creative Commons Attribution NonCommercial License, which permits unrestricted noncommercial use, distribution, and reproduction in any medium, provided the original work is properly cited.

\begin{abstract}
Background: Pharmacovigilance is the science and activities relating to detection, monitoring, assessment, understanding and prevention of adverse effects or any other drug related problem from any pharmaceutical products. The core purpose of pharmacovigilance is to enhance patient care and generate the evidence based information on safety of medicines. The objective of present study was to evaluate the knowledge, attitude and practices of the healthcare professionals about pharmacovigilance and to assess the reasons for underreporting of ADRs.
\end{abstract}

Methods: A cross-sectional study was conducted by administering KAP questionnaire to the healthcare professionals. There were 22 multiple choice questions. Ten related to knowledge, 5 related to attitude, and 6 related to practice. One question was asked to determine the reasons for underreporting of ADRs. The performance in each category was graded as good, average and poor if the number of participants giving correct/positive responses were $>70 \%, 50$ $69 \%,<50 \%$ respectively. Question no 22 was assessed independently to find out reasons for underreporting of ADRs. Data was compiled and analyzed by descriptive statistics, Chi-square and ANOVA test.

Results: The response rate in this study was $62.5 \%$. The study included professors (11\%), associate professors (6\%), assistant professors (20\%), postgraduates $(26 \%)$ and interns $(37 \%)$. That there was statistically very highly significant difference of mean score of knowledge, attitude and practice among health care professionals $(\mathrm{P}<0.001)$. The performance score with respect to attitude of health care professionals towards pharmacovigilance was good as compared to knowledge which was average followed by practice which showed poor performance $(72.5 \%>51.6 \%>36.8 \%)$ ( $\mathrm{p}<0.001)$.

Conclusions: Awareness campaigns, CMEs, workshops on pharmacovigilance should be conducted regularly such that good knowledge about pharmacovigilance can be imparted which can be moulded into good practice.

Keywords: Adverse drug reaction, Attitude, Healthcare professionals, Knowledge, Practice, Pharmacovigilance, Underreporting

\section{INTRODUCTION}

Pharmacovigilance is the science and activities relating to detection, monitoring, assessment, understanding and prevention of adverse effects or any other drug related problem from any pharmaceutical products. ${ }^{1}$ The core purpose of pharmacovigilance is to enhance patient care and generate the evidence based information on safety of medicines. Adverse drug reaction (ADRs) represent the third leading cause of death in USA. ${ }^{2}$ ADRs account for 4.2-30\% of hospital admissions in USA and Canada, 5.7- 
18.8\% in Australila and 2.5-10.6\% in Europe. ${ }^{3}$ A study in India reported overall incidence of $9.8 \%$ ADRs. ${ }^{4}$

India is now considered to be a hub for clinical research. DCGI has shown its commitment to ensure safe use of drugs by establishing the National Pharmacovigilance programme. To detect and spontaneously report ADR and to ensure drug safety, National Pharmacovigilance Program was initiated in India in the year $2004 .^{5}$ It is now renamed as Pharmacovigilance Program of India and operational since July 2010 under the aegis of Central Drug Standard Control Organization. ${ }^{6}$ The Uppsala Monitoring Centre (UMC), Sweden maintains the international database of ADR report received from different countries. India is an active participant in this program and its contribution to UMC database has rose from $0.5 \%$ in 2012 to $2 \%$ in 2013 making it seventh largest contributor of UMC drug safety database. ${ }^{7}$ Although it has shown some improvement, but still lot is required to be done to increase the spontaneous reporting. Spontaneous reporting of ADR by health care professionals is backbone of pharmacovigilance program, but under reporting of ADR is still prevalent and is the cause of concern. A study showed that only $6-10 \%$ of all ADR cases are reported. A Health care professional has major role in pharmacovigilance program. ${ }^{8}$

The information obtained in zonal centres from various peripheral centres is often poor and not well analyzed. There is insufficient research on ADRs in India, so the exact incidence of specific ADRs is unknown. Understanding of ADR reporting system including filling of ADR forms by the health care professionals is almost negligible. To add to this is the total lack of awareness about ADRs and the reporting system in the general population. With more and more clinical trials being conducted in India, there is an immense need to understand the importance of pharmacovigilance and how it impacts the lifecycle of the product. Healthcare professionals, consumer groups and hospitals should appreciate that there is now a system in place to collect and analyze adverse event data. They should start reporting adverse event actively and participate in the national pharmacovigilance program to help ensure that people in India receive safe drugs. For this doctors, pharmacists and nurses are in right position to play a key role in pharmacovigilance program. ${ }^{9,10}$ Previous reported study has found that underreporting of ADR is related with shortcomings in the knowledge and attitude among healthcare professionals. ${ }^{11,12}$ Although many studies in India have evaluated the KAP of pharmacovigilance among healthcare professionals it is imperative to conduct similar studies in teaching hospital of other parts of India to generalize the findings of those studies. ${ }^{13-17}$

\section{Objectives}

- To evaluate the knowledge, attitude and practices of the healthcare professionals about pharmacovigilance in Khaja Bandanawaz Institute of Medical Sciences, Kalaburagi (Karnataka).

- To assess the reasons for underreporting of ADRs.

\section{METHODS}

The study was conducted at KBN teaching and general hospital in Karnataka, South India after taking approval from the Institutional Ethics Committee.

\section{Study design}

This was a cross-sectional questionnaire based study. KAP questionnaire was designed to assess knowledge of pharmacovigilance, attitudes towards pharmacovigilance, and their practice on ADR reporting. There were 22 multiple choice questions. Ten related to knowledge, 5 related to attitude, and 6 related to practice. One question was asked to determine the reasons for underreporting of ADRs. The questions were designed based on earlier studies for assessing KAP of ADR reporting. ${ }^{15-17}$

The questionnaire was pretested on 10 randomly selected healthcare professionals of the hospital. The questionnaire was finalized after ambiguous and unsuitable questions were modified based on the result of pretest.

A score of 1 was allocated for each correct/positive response and score of 0 was allocated for wrong/ unattempted/ negative response. Maximum possible score could be 10, 5 and 6 for KAP, respectively. The overall performance in each category was graded as good, average and poor if the number of participants giving correct/positive responses were $\geq 70 \%, 50-69 \%,<50 \%$ respectively. Question no 22 was assessed independently to find out reasons for underreporting of ADRs.

The participants included interns, postgraduates, physicians and surgeons of all the specialties working in KBNTGH. The purpose of the study was explained to the participants and they were enrolled into the study after they agreed to sign the written informed consent form. A total of 320 questionnaires were distributed to all the participants. Time duration of 24 hours was given to fill the questionnaire.

\section{Statistical analysis}

Data was compiled, entered in Microsoft Excel sheet by using latest version of SPSS and analyzed by descriptive statistics, Chi-square and ANOVA test.

\section{RESULTS}

\section{Response rate}

Out of the 320 questionnaires that were distributed, 200 could be collected back giving us a response rate of $62.5 \%$ 
Figure 1 shows the faculty wise distribution of participants which included professors $(11 \%)$, associate professors $(6 \%)$, assistant professors $(20 \%)$, postgraduates $(26 \%)$ and interns $(37 \%)$.

\section{Knowledge}

Table 1 shows the percentage of participants who gave correct response to the questions related to knowledge of pharmacovigilance. $74 \%$ pf participants knew the correct definition of pharmacovigilance while $43 \%$ knew the actual purpose of it. $80 \%$ participants correctly responded that doctors, nurses, pharmacists can report ADRs.

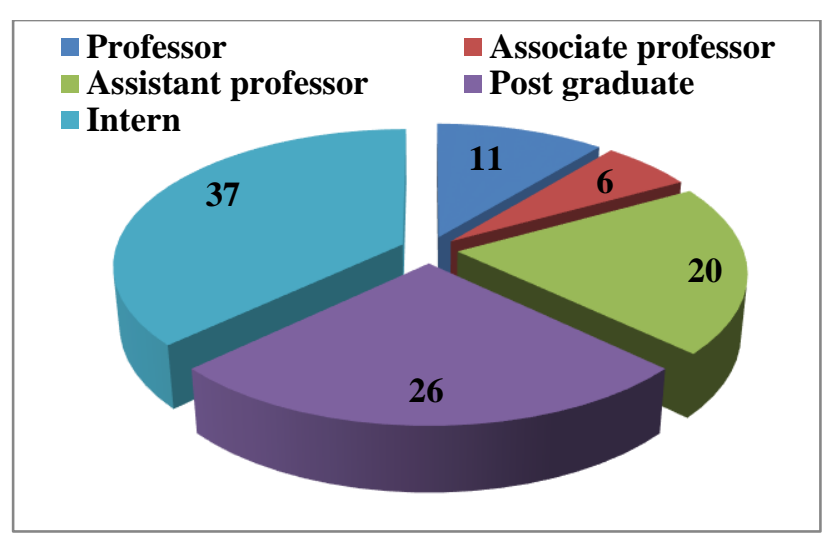

Figure 1: Faculty wise distribution of participants.

Table 1: Response related to knowledge of the participants about pharmacovigilance.

\begin{tabular}{|lll|}
\hline Q. no & Questions & Correct/positive response \\
\hline 1 & Define pharmacovigilance & $74.0 \%$ \\
\hline 2 & The most important purpose of pharmacovigilance is & $43.0 \%$ \\
\hline 3 & $\begin{array}{l}\text { The health care professions responsible for reporting ADRs in hospital } \\
\text { Do you know regarding the existence of a National Pharmacovigilance }\end{array}$ & $60.0 \%$ \\
\hline 5 & $\begin{array}{l}\text { Programme in India? } \\
\text { In India which regulatory body is responsible for monitoring ADRs? }\end{array}$ & $77.0 \%$ \\
\hline 6 & Where the international centre for ADR monitoring is located? & $57.0 \%$ \\
\hline 7 & $\begin{array}{l}\text { A serious adverse event in India should be reported to the regulatory body } \\
\text { within }\end{array}$ & $20.0 \%$ \\
\hline 8 & Rare ADRs can be identified in the following phase of a clinical trial & $42.0 \%$ \\
\hline 9 & $\begin{array}{l}\text { Which of the following methods is commonly employed by the healthcare } \\
\text { professional to monitor adverse drug reactions of new drugs once they are }\end{array}$ & $36.0 \%$ \\
\hline
\end{tabular}

Table 2: Response related to attitude of the participants about pharmacovigilance.

\begin{tabular}{|lll|}
\hline Q. no & Questions & Correct/positive response \\
\hline 11 & Do you think ADR reporting is a professional obligation for you? & $70.1 \%$ \\
\hline 12 & $\begin{array}{l}\text { Do you think Pharmacovigilance should be taught in detail to healthcare } \\
\text { professionals? }\end{array}$ & $83.1 \%$ \\
\hline 13 & $\begin{array}{l}\text { What is your opinion about establishing ADR monitoring centre in every } \\
\text { hospital? }\end{array}$ & $80.5 \%$ \\
\hline 14 & Do you think reporting ADR will increase patient safety? & $84.5 \%$ \\
\hline 15 & Do you think ADR should be reported only if they are serious and rare? & $44.2 \%$ \\
\hline
\end{tabular}

Table 3: Response related to practice of the participants about pharmacovigilance.

\begin{tabular}{|lll|}
\hline Q. no & Questions & Correct/positive response \\
\hline 16 & $\begin{array}{l}\text { Have you anytime read any article on reporting/prevention of adverse drug } \\
\text { reactions? }\end{array}$ & $52.6 \%$ \\
\hline 17 & $\begin{array}{l}\text { Have you ever experienced adverse drug reactions in your patients during } \\
\text { your professional practice? }\end{array}$ & $78.2 \%$ \\
\hline 18 & Have you ever reported ADR to the Pharmacovigilance centre? & $43.1 \%$ \\
\hline 19 & Have you ever seen the ADR reporting form? & $9.5 \%$ \\
\hline 20 & Have you ever been trained on how to report ADR? & $9.5 \%$ \\
\hline 21 & Which method would you prefer to report ADR information? & Refer text \\
\hline
\end{tabular}


There were $67 \%$ of them knew regarding the existence of National Pharmacovigilance programme in India and 77\% of participants knew that CDSCO is the regulatory body responsible for monitonig ADRs in India, while only 57\% of them knew that the international ADR monitoring centre is located in Sweden. Regarding reporting of serious ADRs only $20 \%$ participants could answer correctly that it should be reported with 14 days to the regulatory body in India. $42 \%$ participants had knowledge that rare ADRs of a new drug can be identified only in the phase 4 of clinical trials. Very few health care professionals (36\%) knew that the method employed to monitor ADRs was spontaneous reporting system and even lesser people (20\%) actually knew that a pharmacovigilance committee exits in their institute.

\section{Attitude}

Table 2 shows the percentage of participants who had a positive attitude towards pharmacovigilance activities. $70 \%$ participants think that reporting an ADR is professional obligation on them. While $83 \%$ of them think that pharmacovigilance should be taught to them in detail and $80 \%$ think that the ADR monitoring centres should be established in every hospital. While maximum people (84\%) think that reporting ADR will increase the patient safety, many (44\%) still think that only serious and rare ADRs should be reported.

\section{Practice}

Table 3 shows the response related to practice of healthcare professional with respect to pharmacovigilance.
Among the participants only 52.6\% had read any article related to reporting of ADRs but many (78\%) had experienced some form of ADRs in their patients during their professional practice, while only $43 \%$ of them had reported an ADR to the pharmacovigilance team. Very few healthcare professionals $(9 \%)$ had ever been trained or even seen the ADR reporting form. Regarding the preference of method for reporting ADRs maximum people preferred to contact the pharmacovigilance coordinator followed by the option to upload it directly on the pharmacovigilance website.

\section{Comparison of mean scores of KAP}

Study results show that there was statistically very highly significant difference of mean score of knowledge, attitude and practice in health care professionals $(\mathrm{P}<0.001)$ (Table 4). It was seen that the performance score with respect to Attitude of health care professionals towards pharmacovigilance was good as compared to knowledge which was average followed by practice which showed poor performance $(72.5 \%>51.6 \%>36.8 \%)$. The p-value was $<0.001$ (very highly significant). Study results reveal that, there was statistically very highly significant difference of mean score of knowledge and practice about pharmacovigilance among the faculties of health care professionals $(\mathrm{P}<0.001)$ (Table 5). Mean knowledge and practice scores about pharmacovigilance were significantly good in professors, associate professors and assistant professors as compare to post graduates and interns. The difference of mean score of attitudes towards pharmacovigilance was not statistically significant among the various faculties of health care professionals $(\mathrm{P}>0.05)$.

Table 4: Mean scores of knowledge, attitude and practice of health care professionals about pharmacovigilance.

\begin{tabular}{|lllll|}
\hline Variables & Maximum score & Mean \pm SD & $\%$ of score & Performance \\
\hline Knowledge & 10 & $5.16 \pm 1.74$ & $51.64 \%$ & Average \\
\hline Attitude & 5 & $3.62 \pm 0.96$ & $72.51 \%$ & Good \\
\hline Practice & 6 & $2.21 \pm 1.16$ & $36.83 \%$ & Poor \\
\hline Total & 21 & $11.02 \pm 2.90$ & $52.47 \%$ & \\
\hline ANOVA test, P-value and significance & $\mathrm{F}=13.45 \mathrm{P}=0.000$ Very highly significant & & \\
\hline
\end{tabular}

Table 5: Faculty wise assessment of knowledge, attitude and practice of health care professionals about pharmacovigilance.

\begin{tabular}{|lllll|}
\hline Faculty & No. of samples & $\begin{array}{l}\text { Knowledge } \\
\text { Mean } \pm \text { SD } \\
\% \text { of score }\end{array}$ & $\begin{array}{l}\text { Attitude } \\
\text { Mean } \pm \text { SD } \\
\% \text { of score }\end{array}$ & $\begin{array}{l}\text { Practice } \\
\text { Mean } \pm \text { SD } \\
\% \text { of score }\end{array}$ \\
\hline Professor & 22 & $6.11 \pm 1.92(61.1 \%)$ & $3.73 \pm 1.15(74.6 \%)$ & $3.08 \pm 0.78(51.3 \%)$ \\
\hline Associate professor & 12 & $5.65 \pm 2.73(56.5 \%)$ & $3.71 \pm 1.21(74.2 \%)$ & $2.85 \pm 0.71(47.5 \%)$ \\
\hline Assistant professor & 40 & $5.68 \pm 1.83(56.8 \%)$ & $3.82 \pm 1.33(76.4 \%)$ & $2.52 \pm 0.59(42.0 \%)$ \\
\hline Post graduate & 52 & $4.63 \pm 1.77(46.3 \%)$ & $3.52 \pm 1.09(70.4 \%)$ & $1.73 \pm 0.87(28.8 \%)$ \\
\hline Intern & 74 & $4.15 \pm 2.15(40.5 \%)$ & $3.32 \pm 1.42(66.4 \%)$ & $1.12 \pm 0.83(18.7 \%)$ \\
\hline Total & 200 & $5.16 \pm 1.74(51.64 \%)$ & $3.62 \pm 0.96(72.51 \%)$ & $2.21 \pm 1.16(36.83 \%)$ \\
\hline $\begin{array}{l}\text { ANOVA-test } \\
\text { P-value and significance }\end{array}$ & -- & $\mathrm{F}=7.512$ & $\mathrm{~F}=1.583$ & $\mathrm{~F}=17.341$ \\
\hline VHS: Very High & $\mathrm{P}=0.000, \mathrm{VHS}$ & $\mathrm{P}=0.205, \mathrm{NS}$ & $\mathrm{P}=0.000, \mathrm{VHS}$ \\
\hline
\end{tabular}

VHS: Very Highly Significant; NS: Not Significant 
Figure 2 shows the distribution of various reasons given by the healthcare professionals for not reporting ADRs. While the reasons of healthcare professionals regarding underreporting of ADRs were many, maximum people did not know how to report an ADR $(67 \%)$, followed by lack of remuneration $(23 \%)$ and others.

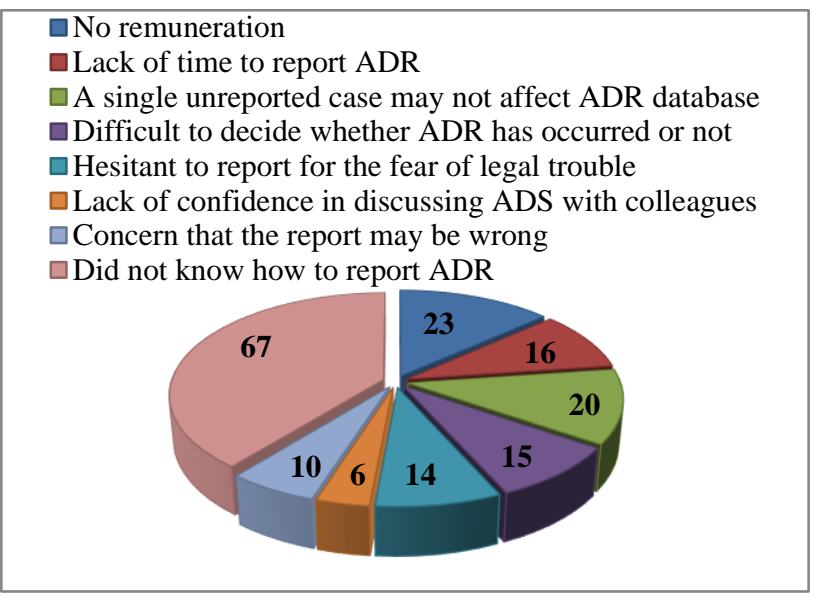

Figure 2: Causation of underreporting of ADRs.

\section{DISCUSSION}

Pharmacovigilance is an important aspect of patient safety which brings reporting of adverse drug reaction even closer to ethical obligations of the healthcare professionals. In the present scenario where there are increasing incidences of legal hassles for doctors and hospitals leading to extravagant compensations due to medical negligence or errors any tool that increases any aspect of patient safety is a boon in long term. Having said that, introspection into our own healthcare system will show us that we are practically nowhere and lack in several aspects of patient safety due to several reasons ranging from lack of infrastructure, remuneration, trained faculty, patient and physician awareness, legal consequences and most importantly willingness to work for patient welfare.

In this study the response rate was average (62.5\%) which somewhat reflects the willingness to work towards patient safety and correlates with other studies where a similar response rate was seen. ${ }^{18,19}$

When we compared the KAP score of the various healthcare professionals we found that though most of them had right attitude towards pharmacovigilance, their knowledge was clearly lacking and that obviously reflected in their practice which was found to be poor. Our analyses echoes with findings of Mukeshkumar B vora, et al. $^{20}$

This brings us to a point where we need to understand that inspite of having right attitude; to achieve the target of holistic health care we need to acquire best knowledge which, when put into practice will ultimately lead to best patient care and safety.
This gap between the knowledge and practice can be filled by conducting CMEs, annual workshops on pharmacovigilance, lectures for undergraduates, by including ADR reporting methodology in pharmacology practicals and atleast two weeks of posting in clinical pharmacology department during internship.

In this study it was seen that there was significant difference between the knowledge and practice of professors, associate professors, assistant professors and postgraduates, interns, while there was no difference in the attitude of various faculties towards pharmacovigilance, which again emphasizes the fact that knowledge is the key to good practice.

One of the main purposes to conduct this study was to analyze the reasons for not reporting ADRs, which came out be many. The primary reason being lack of awareness about the system of reporting and this finding corroborates well with other previous studies. ${ }^{21,22}$ Some other studies noted that lack of time and knowledge about ADRs is often considered to be a cause of underreporting. ${ }^{23,24}$

The problem can clearly be dealt by conducting awareness programmes in various forms and levels where it should be emphasized that every single report matters. Time and again it has been assured that reporting an ADR will not lead to any legal trouble for the reporter, it is still seen as one of the major factors in discouraging physicians from reporting ADRs. While we talk about ethical principles and professional obligations, a large proportion of healthcare professionals still expect that they should have remuneration for reporting ADRs. Although we do not support this strategy, it can still be applied at some level of healthcare system say nurses/interns, where they can be rewarded for achieving monthly /quarterly targets in reporting a certain number of ADRs to the committee. The healthcare professionals should also have adequate competency in identifying ADRs and should not be hesitant in reporting them to the pharmacovigilance committee even in case of inaccuracies or doubts regarding the occurrence of an ADR.

\section{Strengths and limitations of the study}

Though there are number of studies done to assess the KAP of various healthcare professionals our study adds to the fact that pharmacovigilance is yet to take off and spread its feathers and physicians are not inclined enough to take the necessary measures to ensure patient safety through ADR monitoring.

This study did not include nurses and pharmacists in this publication and we realize that they are an important part of healthcare system. It is recommended that further studies should be undertaken to assess their KAP of pharmacovigilance independently. Our study also has the limitations that are inherent to a cross-sectional study by its nature. 


\section{CONCLUSION}

This study showed that though the healthcare professionals had right attitude towards the practice of pharmacovigilance and inturn patient safety they clearly were unaware of its activities and importance which reflected in their average knowledge and poor practice of pharmacovigilance. Hence a very urgent need of awareness campaigns, CMEs, workshops on pharmacovigilance is felt. This can also be done on a regular basis in the form of lectures and practical classes for undergraduates, postings for interns in Clinical Pharmacology Department, and by conducting pharmacovigilance sessions during orientation programme for postgraduates. The Pharmacologists in consultation with higher authorities of the administration should come up with ways and means to mobilize the resources to upscale pharmacovigilance activities in their institute and they should also seek the support of CDSCO and IPC/PvPI for the same.

\section{ACKNOWLEDGEMENTS}

The authors would like to thank the Dean, medical superintendent, administrator of the hospital and heads of all the departments for their kind cooperation during the study. They would also like to thank the statistician for their help in analyzing the results of the study.

\section{Funding: No funding sources}

Conflict of interest: None declared

Ethical approval: The study was approved by the Institutional Ethics Committee

\section{REFERENCES}

1. The World Health Organization. Safety of medicines: A guide to detecting and reporting adverse drug reactions. Geneva; 2002. Available at: http://www.who.int/medicines/areas/quality_safety/sa fety_efficacy/pharmvigi/en/ (Accessed on 2018 sept 02).

2. Makary MA, Michael D. Medical error-the third leading cause of death in the US. BMJ. 2016;353:i2139.

3. Howard RL, Avery AJ, Slavenburg S, Royal S, Pipe $\mathrm{G}$, Lucassen $\mathrm{P}$, et al. Which drugs cause preventable admissions to hospital? A systematic review. Br J Clin Pharmacol. 2007;63:136-47.

4. Arulmani R, Rajendran SD, Suresh B. Adverse drug reaction monitoring in a secondary care hospital in South India. Br J Clin Pharmacol. 2008;65:210-6.

5. Adithan C. National pharmacovigilance programme. Indian J Pharmacol. 2005;37:34.

6. Pharmacovigilance programme of India 2010. CDSCO, Ministry of Health and Family Welfare, Government of India; 2010, Nov. Available at: http://www.cdsco.nic.in/pharmacovigilance. Accessed on 2018 sept 02.
7. Smith CC, Bennett PM, Pearce HM, Harrison PI, Reynolds DJ, Aronson JK, et al. Adverse drug reactions in a hospital general medical unit meriting notification to the Committee on Safety of Medicines. Br J Clin Pharmacol. 1996;42:423-9.

8. Shirodkar SN. India become seventh largest contributor to WHO-UMC's drug safety data base. Available at: http://www.pharmabiz.com. Accessed on 2018 Apr 02.

9. Ahmad SR. Adverse drug event monitoring at the Food and Drug Administration. J Gen Intern Med. 2003;18:57-60.

10. Wysowski DK, Swartz L. Adverse drug event surveillance and drug withdrawals in the United States, 1969-2002: the importance of reporting suspected reactions. Arch Intern Med. 2005;165:13639.

11. Khan SA, Goyal C, Chandel N, Rafi M. Knowledge, attitude and practice of doctors to adverse drug reaction reporting in a teaching hospital in India: An observational study. J Nat Sci Biol Med. 2013;4:1916.

12. Muraraiah S, Rajarathna K, Sreedhar D, Basavalingu D, Jayanthi CR. A questionnaire study to assess the knowledge, attitude and practice of Pharmacovigilance in a paediatric tertiary care centre. J Chem Pharm Res. 2011;3:416-22.

13. Hardeep, Bajaj JK, Kumar R. A survey on the knowledge, attitude and the practice of pharmacovigilance among the health care professionals in a teaching hospital in northern India. J Clin Diagn Res. 2013;7:97-9.

14. Rehan HS, Chopra D, Sah RK, Mishra R. Adverse drug reactions: Trends in a tertiary care hospital. Curr Drug Saf. 2012;7:384-8.

15. Rehan HS, Sah RK, Chopra D. Comparison of knowledge, attitude and practices of resident doctors and nurses on adverse drug reaction monitoring and reporting in a tertiary care hospital. Indian $\mathbf{J}$ Pharmacol. 2012;44:699-703.

16. Gupta P, Udupa A. Adverse drug reaction reporting and pharmacovigilance: Knowledge, attitudes and perceptions among the resident doctors. J Pharm Sci Res. 2011;3:1064-9.

17. Desai CK, Iyer G, Panchal J, Shah S, Dikshit RK. An evaluation of knowledge, attitude, and practice of adverse drug reaction reporting among prescribers at a tertiary care hospital. Perspect Clin Res. 2011;2:12936.

18. Hasford J, Goettler M, Munter KH, MullerOerlinghausen. Physician's knowledge and attitudes regarding the spontaneous reporting system for adverse drug reactions. J Clin Epidemiol. 2000;55:945-50.

19. Cosentino M, Leoni O, Banfi F, Lecchini S, Frigo G. Attitudes to adverse drug reaction reporting by medical practitioners in a Northern Italian district. Pharmacol Res. 1997;35:85-8.

20. Vora MB, Barvaliya M. Knowledge, attitude, and practices towards Pharmacovigilance and adverse 
drug reactions in healthcare professionals of tertiary care hospital, Bhavnagar. Int $\mathbf{J}$ pharm Sci Res. 2014;5(11):820-6.

21. Li Q, Zhang SM, Chen HT, Fang SP, Yu X, Liu D, et al. Awareness and attitudes of healthcare professionals in Wuhan, china to the reporting adverse drug reactions. Chin Med J Engl. 2004;117:856-61.

22. Radhakrishnan R, Vidyasagar S, Verma DM. An educational intervention to assess knowledge attitude practice of pharmacovigilance among healthcare professionals in an Indian Tertiary Care Teaching Hospital. Int J pharmtech Res. 2011;3:678-92.

23. Lopez-Gonzalez E, Herdeiro MT, Figueiras A. Determinants of under-reporting of adverse drug reactions: A systematic review. Drug Saf. 2009;32:1931.

24. Eland IA, Belton KJ, van Grootheest AC, Meiners AP, Rawlins MD, Stricker BH. Attitudinal survey of voluntary reporting of adverse drug reactions. $\mathrm{Br} \mathrm{J}$ Clin Pharmacol. 1999;48:623-7.

Cite this article as: Ghazala Z, Kalshetty $\mathrm{P}$, Vardhamane S. Knowledge, attitude and practices towards pharmacovigilance among health care professionals in a teaching and general hospital of South India. Int J Basic Clin Pharmacol 2019;8:28995. 